\title{
The Grey Clustering Analysis for Photovoltaic Equipment Importance Classification
}

\author{
Hongjiu LIU ${ }^{1} \&$ Qin $\mathrm{ZHANG}^{2}$ \\ ${ }^{1}$ School of Economic and Management, Nanjing University of Aeronautics and Astronautics, Nanjing, China \\ Correspondence: Hongjiu LIU, School of Economic and Management, Nanjing University of Aeronautics and \\ Astronautics, Nanjing, China. E-mail: 891094704@qq.com
}

Received: September 25, 2017

Accepted: October 9, $2017 \quad$ Online Published: October 23, 2017

doi:10.5539/emr.v6n2p47

URL: http://doi.org/10.5539/emr.v6n2p47

\begin{abstract}
The evaluation of equipment importance is an important part of the operation and maintenance management and its purpose is to identify the key equipment which has important influence on the reliable operation of the power station. On the basis of grey clustering theory, the paper firstly establishes the analysis model of photovoltaic (pv) power station equipment importance and the weights of factors in the target hierarchy is solved by using the judgment matrix in analytic hierarchy process. Secondly, according to the whitenization weight function of the grey clustering, pv equipment is classified into three types: key equipment, vital equipment and general equipment, which lays the foundation for the equipment maintenance strategy choice. Finally, an application example verifies the practicality and scientificity of the proposed method.
\end{abstract}

Keywords: equipment importance, grey clustering, judgment matrix, whitening weight function

\section{Introduction}

In recent years, photovoltaic power generation has received the attention of all countries and has developed rapidly with the exhaustion of traditional fossil energy and the management of environmental pollution problems. By the end of 2016, China's photovoltaic power generation capacity was $77.42 \mathrm{GW}$ and new installed capacity was $34.54 \mathrm{GW}$, both of which were the largest in the world. In order to ensure the photovoltaic power station as heavy assets running safely and reliably for a long time, the equipment of the system needs to be inspected and maintained. In general, the selection of equipment maintenance modes is generally based on equipment classification, so equipment importance evaluation is the foundation of equipment maintenance.

The important analysis of equipment is on the premise of the safe operation and is classified based on the importance of equipment, then prepares a table for the corresponding inspection cycles, methods and contents according to different level of equipment importance, which make the equipment maintenance management more scientific.

At present, equipment importance evaluation mainly adopts multipliers and analytical methods which are based on hierarchical analysis and fuzzy clustering analysis. For the system is composed of many correlative and restricted factors, it is difficult to analyze the important degree of equipment with classical mathematics; Otherwise, the second method has the disadvantages of too many subjective parameters and complicated calculation. Therefore, the paper adopts the method of grey clustering to evaluate the importance of equipment.

\section{Brief Introduction of Grey Clustering Method}

Grey clustering is a method that divides some observation indexes or objects into several definable categories based on grey relational matrix or grey white weight function. According to clustering objects, grey clustering can be divided into grey related clustering and grey whitening function clustering. Among them, the grey whitening function clustering is a method to classify the clustering objects based on the white weight function.

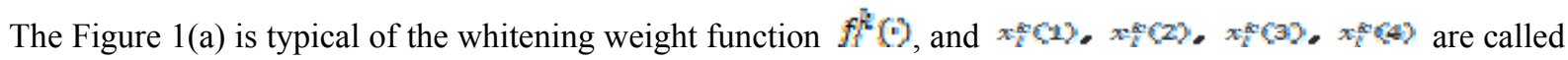

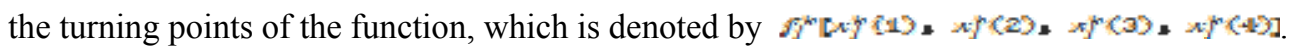


And

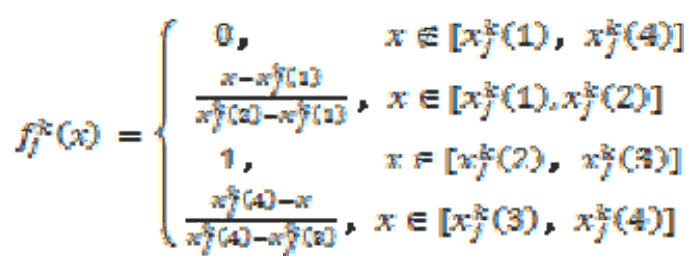

When the whitening function does not have the first and second turning points, as shown in Figure 1(b), this kind of function is called the lower limit measure of the white weight function, which is denoted by $f_{i}[-,-, x(3), x(4)]$.

And

$$
f(x)=\left\{\begin{array}{cl}
0, & x \in\left[0, x_{j}^{k}(4)\right] \\
1, & x \in\left[0, x_{j}^{k}(3)\right] \\
\frac{x_{f}^{k}(4)-x}{x /(4)-x /(8)}, & x \in\left[x_{j}^{k}(3), x_{j}^{k}(4)\right]
\end{array}\right.
$$

When the second turning point overlap with the third turning point, as shown in Figure 1(c), the function is called moderate measure of whitening weight function, which is denoted by $f_{t}^{k}\left[x_{t}^{k}(1) \times x_{t}^{k}(2)--x_{t}^{k}(4)\right]$.

And

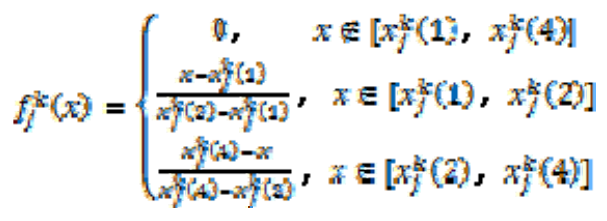

When the whitening function does not have the third and the fourth turning points, as shown in Figure 1(d), this kind of function is called the upper limit measure of the white weight function, which is denoted by $f_{i}^{k}\left[x_{i}^{k}(1), x_{i}^{k}(2),-,-\right]$.

And

$$
f_{f}^{k}(x)=\left\{\begin{array}{cc}
0, & x<x_{j}^{k}(1) \\
\frac{x-x / 1]}{x /(2)-x_{j}(1)}, & x \in\left[x_{j}^{k}(1), x_{j}^{k}(2)\right] \\
1, & x \geq x_{i}^{k k}(2)
\end{array}\right.
$$

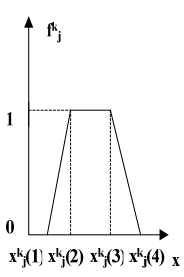

a

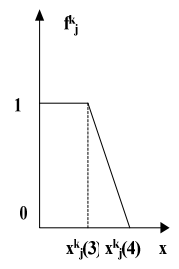

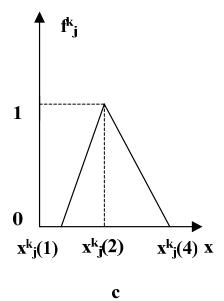

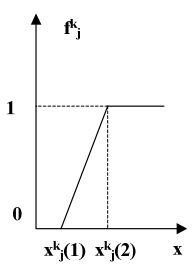

d

Figure 1. Four kinds of whitenization weight function 


\section{Evaluation Model of PV Equipment Importance}

\subsection{Determine Rating Factors}

In the process of the equipment maintenance, the relevant personnel generally choose the reasonable maintenance mode according to the importance of the equipment. In this paper, the importance elements are adopted to describe the equipment importance. Important degree of each equipment can use multiple elements to describe importance, at the same time, the importance of each important expression can choose different devices for implementation.

These indexes, such as failure rate, maintenance cost, monitoring, downtime, loss of stop and replacement parts supply are generally selected to determine the elements in the importance of photovoltaic power station equipment.

\subsection{Determine the Weight of Indicators}

In this paper, analytic hierarchy process is used to determine the weight distribution of evaluation factors. Firstly,

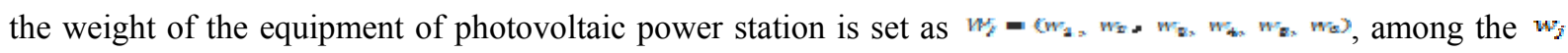
represents the weight of index $\mathbf{j}$ on the target level and satisfies $\Sigma_{q_{-}} w_{s}=1, w_{j} \in(0,1)$. Then the judgment matrix $\mathrm{H}$ of indices will be constructed. The judgment value is determined by A. L. Saaty's "1 9" scaling (Table 1) and the weight value is obtained by the square root method. To ensure the validity of matrix $\mathrm{H}$, the

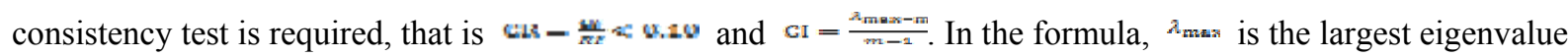
of the matrix $\mathbf{H}$, and $m$ is the order of the matrix H. Values of $k t$ are looked up among the average random consistency index (Table 2).

Table 1. "1 9" Scaling

\begin{tabular}{cc}
\hline Scaling & Meaning \\
\hline 1 & Equally importance \\
3 & Weak importance \\
5 & Quite importance \\
7 & Very importance \\
9 & Absolute importance \\
$2,4,6,8$ & Medial values \\
\hline
\end{tabular}

Table 2. Average random consistency index

\begin{tabular}{cccccccccc}
\hline Order & 1 & 2 & 3 & 4 & 5 & 6 & 7 & 8 & 9 \\
\hline RI & 0 & 0 & 0.58 & 0.90 & 1.12 & 1.24 & 1.35 & 1.41 & 1.45 \\
\hline
\end{tabular}

\subsection{Determine the Specific Cluster Level k}

According to $\mathrm{ABC}$ classification, the equipment is divided into three levels: key equipment, vital equipment and general equipment.

\subsection{Determine the Clustering Value Matrix of the Cluster Object of Photovoltaic Power Station Equipment}

Through the discussion with the staff who are on site operation and maintenance, each factor score according to the actual situation of will be given in this paper and can be modified in the future according to the feedback information. On the basis of the references, the evaluations standard of the various factors for all equipment are shown in the Table 3. According to the Table 3 , the clustering objects are graded according to the scoring criteria in Table 3, then the clustering value matrix of clustering objects can be obtained. 
Table 3. Criteria for all factors

\begin{tabular}{ccccccc}
\hline Serial number & failure rate & scores & maintenance cost & scores & monitoring & scores \\
\hline 1 & $<3 \%$ & 10 & $<1000$ & 10 & easy & 10 \\
2 & $3 \% \sim 10 \%$ & 50 & $1000 \sim 10000$ & 40 & general & 50 \\
3 & $10 \% \sim 40 \%$ & 70 & $10000 \sim 50000$ & 80 & difficult & 75 \\
4 & $>40 \%$ & 100 & $>50000$ & 100 & very difficult & 100 \\
\hline Serial number & Downtime (hours/day) & scores & loss of stop & scores & replacement parts supply & scores \\
\hline 1 & $<2$ & 20 & small & 10 & $<2$ & 10 \\
2 & $2 \sim 6$ & 50 & general & 60 & $2 \sim 4$ & 50 \\
3 & $6 \sim 10$ & 70 & large & 80 & $6 \sim 10$ & 75 \\
4 & $10 \sim 24$ & 100 & very large & 100 & $>10$ & 100 \\
\hline
\end{tabular}

\subsection{Determine the Grey Class}

In order to describe the grey class, the clustering index $\mathrm{j}$ is required to specify its albino function by clustering class $\mathrm{k}$.

(1) The determination of whitenization weight function can be divided into three steps: I identify the boundaries of specific grey categories; II determine the basic form of the albino weight function; III determine the turning point of the albino weight function.

(2) Calculate the critical value of the grey class $\lambda_{i}^{2}$.

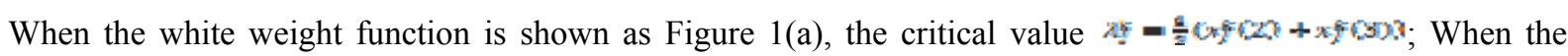

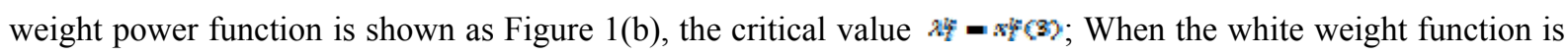
shown as Figure 1(c) and 1(d), the critical value $\lambda_{I}^{k}=x_{i}^{\mathrm{k}}(2)$.

(3) Calculated the standard weight of index $\eta_{f}^{\mathrm{Z}}$.

By definition, the formula for the standard weight $\eta_{f}^{k}$ of the 1 index on the $\mathrm{k}$ level is

(4) Calculate the clustering coefficient $\sigma_{i}^{k}$.

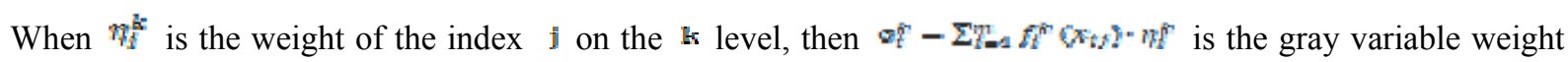
clustering coefficient of $\mathbf{i}$ object on the level $\mathbf{k}$.

(5) Calculate the clustering coefficient right $\sigma_{t}$, then determine the grey clustering weight matrix $\Sigma$.

In general, $\sigma_{t}=\left\lfloor\sigma_{i}^{2}, \sigma_{i}, \ldots, \sigma_{i}^{a *}\right]$ is the clustering coefficient vector of clustering object $\mathbf{i}$, and the clustering coefficient matrix $\Sigma=\left[v_{i}^{k}\right]$, that is

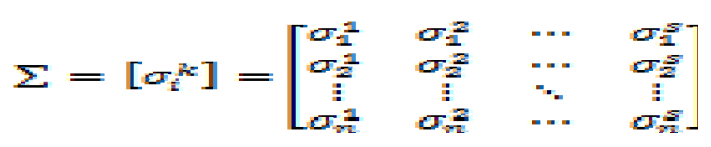

\subsection{Synthesize Clustering Conclusions}

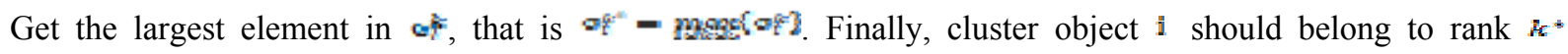
according to

\section{Application Case}

With a $1 \mathrm{kw}$ power station project as an example, equipment will be rated according to Table 3 criteria will clustering objects on the basis of the equipment operation and maintenance of historical records and related data, then it will get six types of power station equipment's evaluation values, which are shown in Table 4. According to the importance of the equipment, it can be divided into three levels $(k=(1,2,3)\}:$ key equipment, vital 
equipment and general equipment. Grading indicators have failure rate, maintenance cost, monitoring, downtime, loss of stop, and replacement parts supply.

Table 4. The evaluation value of the equipment on the indicators

\begin{tabular}{ccccccc}
\hline equipment & failure rate & maintenance cost & monitoring & down time & loss of stop & replacement parts supply \\
\hline $1^{\#}$ & 50 & 80 & 50 & 70 & 100 & 75 \\
$2^{\#}$ & 10 & 40 & 10 & 50 & 80 & 10 \\
$3^{\#}$ & 10 & 40 & 75 & 20 & 10 & 10 \\
$4^{\#}$ & 70 & 10 & 75 & 50 & 80 & 50 \\
$5^{\#}$ & 10 & 10 & 50 & 20 & 60 & 50 \\
$6^{\#}$ & 100 & 80 & 100 & 100 & 100 & 100 \\
\hline
\end{tabular}

\subsection{Determine the Albino Function}

According to the formula (1) (4), the white weight function of the failure rate of the plant is $f_{2}^{2}=\left[42,80_{2}-n_{2}\right]$, $f_{2}^{s}=\left[21,4 z_{2}-80,1, f_{1}^{\mathbb{E}}=[-,-21,42]\right.$. Other indicators are similar.

\subsection{Determine the Weight of All Indicators}

According to the operation of each equipment, maintenance history and related reliability database, the judgment matrix $\mathrm{H}$ of each factor weight is obtained through discussion with personnel who are on site operation and maintenance.

$$
\mathrm{H}=\left[\begin{array}{cccccc}
1 & 1 / 2 & 2 & 3 & 1 & 2 \\
2 & 1 & 3 & 2 & 2 & 3 \\
1 / 2 & 1 / 3 & 1 & 3 & 1 & 2 \\
1 / 3 & 1 / 2 & 1 / 3 & 1 & 1 & 2 \\
1 & 1 / 2 & 1 & 1 & 1 & 2 \\
1 / 2 & 1 / 3 & 1 / 2 & 1 / 2 & 1 / 2 & 1
\end{array}\right]
$$

The value of matrix corresponds to the result of comparison among failure rate, maintenance cost, monitoring, downtime, loss of stop, and replacement parts supply. The weight of a factor is calculated, that is $W_{3}-\left(w_{3}, w_{2}, w_{2}, w_{4}, w_{3}, w_{2}\right)=W_{l}=(0.204,0.309,0.151,0.105,0.151,0.079)$, amount of inspection $\lambda_{\max }=6.304, \quad c I=0.061$, $\mathrm{CR}=0.048<0.10$, so it is through the consistency test. If other types of equipment are classified, the weights of corresponding indexes can be calculated according to the above methods.

\subsection{Determine the Gray Variable Weight Coefficient of Clustering Object on Cluster Class}

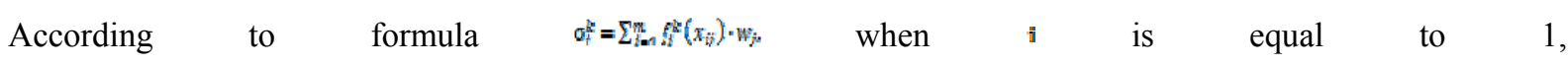
$\sigma_{1}^{1}=f_{1}^{1}(50) \times 0.204+f_{2}^{1}(80) \times 0.309+f_{2}^{1}(75) \times 0.151+f_{4}^{1}(20) \times 0.105+f_{n}^{\prime \prime}(10) \times 0.151+f_{6}^{1}(10) \times 0.079=0.623$.

By the same token,

$$
\sigma_{1}^{2}=0.330, \quad \sigma_{1}^{2}=0.050
$$

So,

$$
\left.\sigma_{1}=\left[\mu_{1}^{2}, \varepsilon_{1}^{2}, \omega_{1}^{\mathrm{N}}\right]\right]=[0.623,0.350,0.650]
$$

The same calculation,

when $\mathbf{i}$ is equal to 2 ,

$$
\left.\sigma_{2}=\left[\sigma_{2}^{3}, \sigma_{f}, \sigma_{8}\right]\right]-[0,043,(1,470,0,491]
$$

when $\mathbf{i}$ is equal to 3 , 


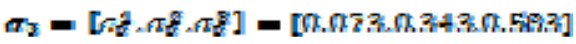

when $\mathbf{i}$ is equal to 4 ,

$$
\sigma_{4}=\left[\sigma_{4}, \sigma_{8}, \sigma_{8}\right]-[0.269,0.413,0.3: 17]
$$

when 1 is equal to 5 ,

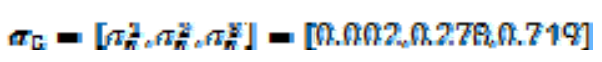

when 1 is equal to 6 ,

$$
\sigma_{s}=\left[\omega_{0}^{2}, \omega_{0}^{2}, \omega_{0}^{\mathbb{V}}\right]=[1,0,0]
$$

\subsection{Construct the Grey Clustering Weight Matrix of Cluster Objects}

According to the formula (5), grey clustering weight matrix $\Sigma$ is available:

$$
\sum=\left[\sigma_{i}^{k}\right]=\left[\begin{array}{cccc}
\sigma_{1}^{1} & \sigma_{1}^{2} & \ldots & \sigma_{1}^{s} \\
\sigma_{2}^{1} & \sigma_{2}^{2} & \ldots & \sigma_{2}^{s} \\
\vdots & \vdots & \vdots & \vdots \\
\sigma_{n}^{1} & \sigma_{n}^{2} & \ldots & \sigma_{n}^{s}
\end{array}\right]=\left[\begin{array}{ccc}
0.623 & 0.330 & 0.050 \\
0.043 & 0.470 & 0.491 \\
0.073 & 0.343 & 0.583 \\
0.269 & 0.413 & 0.317 \\
0.002 & 0.278 & 0.719 \\
1 & 0 & 0
\end{array}\right]
$$

\subsection{Belong to Equipment Important Grade}

For the maximum clustering coefficient $\omega_{f}^{z^{*}}$ in the cluster vector $\sigma_{i}$, the $k^{*}$ grade is belonging to $\sigma_{f}^{\sigma^{*}}$ of the six equipment of the power station, as shown in Table 5. As can be seen from the table, equipment $1^{*}$ and $6^{*}$ belong to key equipment, equipment $4^{*}$ belongs to the vital equipment, the rest of the equipment $2^{\#}, 3^{*}$ and equipment $5^{\#}$ belong to general equipment.

Table 5. The clustering coefficient of equipment important of a $1 \mathrm{KW}$ power station

\begin{tabular}{ccccc}
\hline Equipment & 1 & 2 & 3 & $k k^{*}$ \\
\hline $\mathbf{1}^{*}$ & 0.623 & 0.330 & 0.050 & 1 \\
$\mathbf{2}^{*}$ & 0.043 & 0.470 & 0.491 & 3 \\
$\mathbf{3}^{*}$ & 0.073 & 0.343 & 0.583 & 3 \\
$\mathbf{4}^{*}$ & 0.269 & 0.413 & 0.317 & 2 \\
$\mathbf{5}^{*}$ & 0.002 & 0.278 & 0.719 & 3 \\
$\mathbf{6}^{*}$ & 1 & 0 & 0 & 1 \\
\hline
\end{tabular}

\section{Conclusion}

Considering the fuzzy characteristics of each factor of equipment importance, this paper proposes a grey clustering analysis method to evaluate the importance of equipment. Finally, photovoltaic power station equipment is classified into three kinds: key equipment, vital equipment and general equipment. The application case shows that the method is an effective way to solve the problem of equipment importance evaluation, which provide the basis for further maintenance decision-making, as well as provides scientific basis for maintenance management and optimizes allocation of maintenance resources at the same time. 


\section{References}

Dong, F., Xiao, M., \& Liu, B. (2010). Construction method of whitenization weight function in grey system teaching. Journal of North China Institute of Water Conservancy and Hydroelectric Power, 31(3), 97-99.

Dong, Y., Gu, Y., \& Yang, K. (2003). Criticality analysis of on equipment in power plant based on monte carlo simulation. Proceedings of the CSEE, 23(8), 205-210.

Guo, Y. Z., \& Feng, S. (1995). The fuzzy clustering analysis for chemical apparatus importance classification. Journal of Southeast University, 25(3), 96-101.

Hui, S. G., Xi, P. Q., \& Hui, F. W. (2014). Based on Reliability Importance Measures Method of Comprehensive Evaluation of Electric Power Communication Equipment. Applied Mechanics and Materials, 496(500), 2725-2728.

Jin, K. (2015). The application of fuzzy analytic hierarchy process in the evaluation of the important degree of API equipment. Mechanical and Electrical Information, 1(2), 48-52.

Li, G. Z., Tan, N., \& Zhang, J. B. (2012). Criticality analysis of subway train equipment based on improved analytical hierarchy process. Journal of Electronic Measurement and Instrument, 26(6), 503-507. https://doi.org/10.3724/SP.J.1187.2012.00503

Liu, J., Wang, M., \& Gu, Y. (2012). Maintenance logical decision of wind farm equipment based on the TOPSIS criticality analysis. Renewable Energy Resources, 30(12), 29-34.

Liu, S. F., Dang, Y. G., \& Fang, Z. G. (2010). Grey system theory and its application (5th ed.). Beijing: Science press.

Liu, S. F., \& Xie, N. M. (2008). New grey evaluation method based on improving triangulation function. Journal of Systems Engineering, 26(2), 244-250.

Yang, H., Jing, J. Q., \& Tang, Z. W. (2017). An analysis of the importance of subway train equipment based on improved AHP. China Petrochem, 4(1), 156-157.

\section{Copyrights}

Copyright for this article is retained by the author(s), with first publication rights granted to the journal.

This is an open-access article distributed under the terms and conditions of the Creative Commons Attribution license (http://creativecommons.org/licenses/by/4.0/). 